\title{
Article
}

\section{A cross-country survey of attitudes toward childbirth technologies and interventions among university students}

Stoll, Kathrin, Edmonds, Joyce, Sadler, Michelle, Thomson, Gillian, McAra-Couper, Judith, Swift, Emma M., Malott, Anne, Streffing, Joana, Gross, Mechthild M. and Downe, Soo

Available at http://clok.uclan.ac.uk/24093/

Stoll, Kathrin, Edmonds, Joyce, Sadler, Michelle, Thomson, Gillian ORCID: 0000-0003-3392-8182, McAra-Couper, Judith, Swift, Emma M., Malott, Anne, Streffing, Joana, Gross, Mechthild M. et al (2019) A cross-country survey of attitudes toward childbirth technologies and interventions among university students. Women and Birth, 32 (3). pp. 231-239. ISSN 1871-5192

It is advisable to refer to the publisher's version if you intend to cite from the work. http://dx.doi.org/10.1016/j.wombi.2018.07.025

For more information about UCLan's research in this area go to

http://www.uclan.ac.uk/researchgroups/ and search for <name of research Group>.

For information about Research generally at UCLan please go to http://www.uclan.ac.uk/research/

All outputs in CLoK are protected by Intellectual Property Rights law, including Copyright law. Copyright, IPR and Moral Rights for the works on this site are retained by the individual authors and/or other copyright owners. Terms and conditions for use of this material are defined in the policies page. 


\section{A cross-country survey of attitudes toward childbirth technologies and interventions among university students}

\section{Abstract}

Problem \& Aim: Cultural beliefs that equate birth technology with progress, safety and convenience contribute to widespread acceptance of childbirth technology and interventions.

Little is known about attitudes towards childbirth technology and interventions among the next generation of maternity care users and whether attitudes vary by country, age, gender, childbirth fear, and other factors.

Methods: Data were collected via online survey in eight countries. Students who had never had children, and who planned to have at least one child were eligible to participate.

Findings: The majority of participants $(n=4569)$ were women $(79.3 \%)$, and the median age was 22 years. More than half of students agreed that birth technology makes birth easier $(55.8 \%)$, protects babies from harm $(49.1 \%)$ and that women have a right to choose a medically nonindicated cesarean (50.8\%).Respondents who had greater acceptance of childbirth technology and interventions were from countries with higher national caesarean birth rates, reported higher levels of childbirth fear, and were more likely to report that visual media or school-based education shaped their attitudes toward birth. Positive attitudes toward childbirth technology and interventions were also associated with less confidence in knowledge of birth, and more common among younger and male respondents.

Discussion/Conclusion: Educational strategies to teach university students about pregnancy and birth in ways that does not frighten them and promotes critical reflection about childbirth technology are needed. This is especially true in countries with high rates of interventions that reciprocally shape culture norms, attitudes, and expectations.

Keywords: Birth, technology, attitude, young adults, survey 


\section{Statement of Significance (total of $\mathbf{1 0 0}$ words)}

\begin{tabular}{|l|l|}
\hline Problem or Issue & $\begin{array}{l}\text { The use of childbirth technology and interventions is on } \\
\text { the rise in most high-income countries. }\end{array}$ \\
\hline What is Already Known & $\begin{array}{l}\text { Attitudes towards childbirth and preferences for care are } \\
\text { well-developed among young men and women prior to } \\
\text { pregnancy. }\end{array}$ \\
\hline What this Paper Adds & $\begin{array}{l}\text { Findings from this paper show that favourable attitudes } \\
\text { toward childbirth technology and interventions varied } \\
\text { across countries, were more common among younger and } \\
\text { male respondents, were linked to childbirth fear, higher } \\
\text { national caesarean birth rates, and reports that visual } \\
\text { media or school-based education shaped students' } \\
\text { attitudes toward birth. }\end{array}$ \\
\hline
\end{tabular}




\section{Introduction}

Technology is defined as the creation and use of technical means and their interrelation with life, society, and the environment, and the application of this knowledge for practical ends (1). Technology used during labour and birth varies widely, from simple tools and techniques in traditional societies, to a complex set of specialized techniques and instruments in modern societies (2). Knowledge gained from technology is often regarded as objective, free of bias and superior (3). Sophisticated technology introduces new conceptions of what counts as relevant information and new judgments about who is competent to interpret information, to communicate it, and to make decisions regarding the management of birth. (4) These discourses can undermine women's confidence in their ability to give birth without obstetric interventions $(5,6)$. Jordan and Thatcher argue that use of technology is supported by ideologies promoting 'modernization' and 'progress' (7). These ideologies contribute to the acceptance of childbirth technology because of its perceived capacity to reduce and control the uncertainties, discomforts and risks of childbirth $(3,8-10)$.

The pervasiveness of risk discourse in pregnancy and childbirth $(11,12)$ has resulted in an "ever-narrowing window of normality" $(13)$ ( $p$. 207) and a precautionary approach to the management of pregnancy, labour and birth. Although adverse childbirth outcomes are relatively rare in middle and high-income countries, risk discourses are prevalent and intensifying $(14,15)$, impact on women's choices for where and how to give birth (16) and can undermine women's confidence to give birth without interventions $(5,6)$.

Cultural norms that value technological advances are pervasive in high and middle-income countries and are reflected in current birth practices. Almost all women in high income countries give birth at hospitals, assisted by technologies such as fetal monitors, pharmacological agents to induce or augment labour, and epidurals for labour pain (17). Although institutional births are the norm, attitudes toward technology among maternity care users vary widely. Some childbearing women perceive technology as a resource to control their birth experience, and view interventions as a "liberation from the tyranny of biology" (18) (p.1137) . In contrast, other women actively resist childbirth technology and want to birth in their own homes, surrounded by family and without interventions (19). Most women likely fall somewhere between these two poles as their relationship with technology is shaped by conflicting meanings because "contemporary childbirth is dominated by a variety of discourses -medicalisation, natural childbirth, androcentric models, woman-centered models and risk" (20) (p.487). These differences tend to be more explicit at a theoretical level in academic papers and books, but in practice, their edges are more blurred. (20) 
The focus of this paper is how childbirth technology and interventions are viewed by university students from eight OECD countries with different maternity care systems. Similar to pregnant women, the next generation of maternity care consumers report divergent attitudes towards obstetric interventions. Young women who plan to become pregnant in the future and who report high levels of childbirth fear tend to prefer obstetric interventions, such as cesarean births, because they offer the promise to control/avoid pain and bodily damage perceived to be associated with vaginal birth. $(21,22)$ In contrast, young Canadian women with high confidence in their ability to cope with labour and birth and those who felt that birth is a natural and normal life event tended to view obstetric technology more critically, and believed that it should be used judiciously, and only if necessary (23). Regardless of levels of childbirth fear or confidence in birth, young Canadian women placed a high value on respecting women's choices during childbirth, including the decision to have a cesarean birth without medical indications.(21) Elevated perceptions of childbirth risks among Canadian and US students were linked to higher rates of preferences for cesarean birth $(24,25)$. These insights suggest that attitudes towards obstetric technology differ depending on perceptions of risk and levels of childbirth fear, with the exception of women's rights to self-determination and autonomous decision-making, which is endorsed by the majority of young Canadian women who plan to have children. (21) Beyond the Canadian context, little is known about the attitudes towards obstetric technology among the next generation of maternity care consumers.

\section{Rationale and study objectives}

Research suggests that childbirth interventions in high income countries are on the rise and pregnant women's willingness to accept obstetric interventions has increased significantly over time (26). In low income countries women typically receive fewer interventions ('too little, too late'). Women from vulnerable populations, in low, middle and high-income countries are more likely to experience a delay in accessing interventions. In high and middle income countries the current over-use of childbirth interventions and technology is commonly described as 'too much, too soon' and efforts to reduce rates of unnecessary interventions in childbirth are underway (27). Such strategies, however, are dependent on a diversity of structural, institutional and individual factors, including -among others- national health systems as a whole, hospital cultures and the willingness of maternity care providers and maternity care users to consider a less technological approach to birth as a safe option. 
Our target population, i.e. men and women between the ages of 17-40 who plan to have children are the next generation of maternity care users, and so their views about the utility, or even necessity, of childbirth technology and interventions could, in theory, accelerate the use of such technology and interventions in maternity care. It is therefore important to establish how childbirth technology and interventions are perceived by women and men who plan to have children in a range of settings, as a basis for future childbirth education, and service planning. A key assumption is that prior to pregnancy university students develop attitudes toward childbirth technology and interventions that are socially constructed, i.e. informed by socio-cultural experiences and teachings.

To this end, we characterize and compare attitudes about childbirth technology and interventions among university students prior to pregnancy in eight OECD countries. We then explore factors that might be linked to attitudes toward childbirth technology and interventions, including gender, age, influential sources of information about pregnancy and birth, childbirth fear and national cesarean section rates (as a proxy for local cultural norms about technological intervention in childbirth).

\section{Methods}

An online survey was used to collect data at ten universities/colleges in eight countries: two universities in Canada and Germany, and one university each in Australia, Chile, England, Iceland, New Zealand and the United States. The Australian university funded the project. We included countries with a range of different maternity care systems and rates of childbirth interventions. For example, Iceland has the lowest Cesarean section rate among OCED countries (15.2\%) and Chile among the highest (44.7\%) (28). Germany, England, Australia, Chile, New Zealand and Iceland have very high midwifery coverage while Canada and the US have relatively low midwifery coverage.

Data collection took place between 2014 and 2015. An invitation to participate in the survey was sent via e-mail to either all students at the university or a subsample of students. At some universities the request to participate was sent by enrollment services, at other universities the study advertisement was sent out by departmental administrators or posted on university websites. In Germany, Chile and Iceland the survey was forward backward translated as per WHO guidelines. (29) The forward-backward translation of the survey and participant recruitment are described in more detail elsewhere (30-32). Data were collected from all students who responded to the survey and met eligibility criteria. University students who were already parents or pregnant at the time of data collection or did not express a desire to have 
children in the future as well as anyone over the age of 40 were excluded. Survey items measured socio-demographic characteristics, childbirth fear, attitudes about childbirth technology and interventions, sources of information about pregnancy and birth that shaped students' attitudes toward birth, and confidence in knowledge of pregnancy and birth. The study protocol was approved by university ethics committees in each participating country.

\section{Measurement}

The survey instrument was adapted from a Canadian survey about childbirth attitudes that was completed by 3680 students at a university in Western Canada in 2006. In the current version of the survey students responded to 22 items that measured attitudes towards birth on a six-point Likert scale. Most of these items were first used in the 2006 version of the survey, either verbatim or with small changes in wording (see Table 1).

Attitudes toward childbirth technology and interventions: Students were asked to respond to six items that assessed attitudes toward childbirth technology and interventions on a six-point Likert scale (ranging from strongly disagree to strongly agree). Five items examined acceptance/support for the use of childbirth technologies and interventions. One item reflected a preference for judicious use of technology (see items 9-13 and item15 in Table 1).

Childbirth fear: Fear of childbirth was measured with the 10-item Childbirth Fear Prior to Pregnancy Scale (CFPP) (30) (see items 1-8 and items 21 and 22 in Table 1). The scale assesses fear of pain and being out of control, fear of complications and fear of physical damage as a result of childbirth. Only those respondents who completed all items of the scale received a summary score. In other words, students who missed one or more item were excluded from analysis involving the CFPP score. The CFPP has high internal consistency reliability (as measured with Cronbach's alpha) when assessed in six independent student samples. It showed good construct validity, as indicated by a strong positive correlation between CFPP scores and another measure of childbirth fear, and a weak positive relationship between CFPP scores and measures of anxiety, depression and stress (30). A detailed description of scale construction and psychometric testing of the CFPP scale has been published elsewhere (30).

Sources of information that shaped students' attitudes toward pregnancy \& birth 
Students were asked whether visual media, written media, experiences of family or friends and school-based health/sex education shaped their attitudes toward pregnancy and birth (response options were yes or no; students could check multiple responses). Students were also asked to note if they had ever witnessed a (human) birth first hand.

Confidence in level of knowledge of pregnancy and birth: Students were asked to rate their confidence in their level of knowledge of pregnancy and birth on a six-point scale, ranging from strongly disagree to strongly agree. This variable was recoded into two categories: agreement (which comprised response options 'somewhat agree, agree and strongly agree') versus disagreement (which comprised response options 'somewhat disagree, disagree and strongly disagree').

\section{Data analysis}

We report on age, region of birth, field of study, highest level of education and marital status for the full sample. Next, we describe attitudes toward childbirth technology and interventions for the full study sample and stratified by country using a standardized cohort (female students, age 18-25, who were born in the country they responded from; 2310 students), to adjust for differences in the demographic profile of students who participated in different countries. We recoded the six Likert response options of each item as follows: students who agreed or strongly agreed with the item received a score of 1 and those who somewhat agreed, somewhat disagreed, disagreed or strongly disagreed received a score of 0 . We opted to recode the items in this way to identify students who expressed clear and unambiguous support for obstetric technology and interventions. We then calculated childbirth fear scores across samples and the proportion of students across countries whose attitudes toward pregnancy and birth were shaped by different sources of information.

Chi-Square analyses were undertaken to examine the relationship between attitudes toward childbirth technology and interventions (six items) and 1) sources that shaped students' attitudes toward pregnancy and birth, 2) moderate/high childbirth fear (CFPP scores $>75^{\text {th }}$ percentile) versus no/low childbirth fear (CFPP scores at or below the $75^{\text {th }}$ percentile, 3 ) moderate to high confidence in knowledge of pregnancy and birth (students who strongly agreed, agreed or somewhat agreed with the statement 'I feel confident about my level of knowledge around pregnancy and birth') versus no or low confidence (students who strongly disagreed, disagreed or somewhat disagreed with the statement). Next, we computed Spearman's correlation coefficient $\left(\mathrm{S}_{\mathrm{r}}\right)$, to examine whether students residing in countries with higher cesarean birth rates 
reported stronger support for childbirth technology and interventions. $\mathrm{P}$ values $<0.01$ were deemed significant, because of the relative large number of statistical comparisons. Finally, we ranked each country on each item that assesses attitudes towards childbirth interventions and then summed the rankings, to determine in which countries students reported the most versus the least support for childbirth technology and interventions overall.

\section{Results}

A total of 4569 students who met eligibility requirements completed the survey. The fewest number of responses were contributed from Canadian students (5.7\%) and the largest proportion from German students (21.5\%). The majority of respondents were women (79.3\%) and most were born in the country where data was collected (83.4\%). The median age of respondents was 22 years old $\left(5^{\text {th }}\right.$ percentile: $18 ; 95^{\text {th }}$ percentile: 32) and ranged from 20 in the USA to 28 in Chile. Additional socio-demographic characteristics are reported in Table 2.

The proportion of students in each country, who agreed with each item are listed in Table 3, for the full sample and for the standardized cohort. Approximately half of the full sample agreed that birth technology makes birth easier (55.8\%), protects babies from harm (49.1\%) and that women have a right to choose a medically non-indicated cesarean (50.8\%). In contrast, only $21.7 \%$ agreed that childbirth requires reliance on medical interventions and only $9.2 \%$ agreed that birth technology is necessary to deliver a baby. Based on a review of standard deviations of each item (results not shown) we found that students reported the least variation around the mean for items 'Birth technology makes birth easier' and 'Birth technology protects my baby from harm' and the most variation for the items 'Birth technology should only be reserved for those women who need it' and 'I believe it is a woman's right to choose a cesarean birth, even if there are no medical indications'.

\section{Attitudes toward childbirth technology and interventions by gender and age}

Overall, men were significantly more likely to value childbirth technology and interventions compared to women. For instance, $56.9 \%$ of men versus $47.4 \%$ of women agreed that birth technology protects babies from harm $(p<0.001)$ and $61.2 \%$ of men versus $48.3 \%$ of women believed that it is a woman's right to choose a cesarean birth even if there are no medical indications $(p<0.001)$. 
Attitudes also varied by age: students aged between $17-24$ years were significantly $(p=0.01)$ more likely to agree that birth technology makes birth easier compared to older students. Similarly, students aged 17-20 years were significantly more likely to agree that women have the right to opt for a cesarean birth without medical indication, compared to older students. Students over 25 years old were significantly more likely to agree that birth technology should only be reserved for women who need it $(p<0.001)$; however 30-40 year old students were twice as likely to agree that birth technology is necessary to deliver a baby, compared to students 25 or younger $(p<0.001)$.

\section{Attitudes toward childbirth technology and interventions across cultures}

Attitudes toward childbirth technology and interventions varied across countries (Table 3). For example, a greater proportion of students from the US (73.6\%) agreed that birth technology makes birth easier compared to students from the other countries. Icelandic students had the lowest rate of agreement (34.7\%) with the statement 'I believe it is a woman's right to choose a cesarean even if there are no medical indications' relative to students from the other countries - Australian, US, and Chilean students had the highest rate of agreement (61.4-63.2\%). Overall, students in the US held the most accepting and supportive attitudes toward childbirth technology and interventions while students from New Zealand held the least accepting and supportive attitudes (Table 4).

When correlating attitudes with national cesarean rates, students who supported the view that it is a woman's right to choose a cesarean birth in the absence of medical indications were significantly more likely to reside in countries with higher national cesarean rates $\left(r_{s}=0.186 p<0.001\right)$. Weaker, but significant correlations were also observed between higher cesarean rates and agreement with the statements about technology making birth easier and childbirth requiring reliance on medical interventions even in uncomplicated pregnancies $\left(r_{s}=0.05\right.$ $p=0.01$ and $r_{s}=0.05, p=0.02$, respectively).

\section{Attitudes toward childbirth technology and interventions and sources of information that shaped students' attitudes toward pregnancy \&} childbirth 
In each country, the stories and experiences of family members were the most frequently cited source of influential information about pregnancy and childbirth (Fig. 1). Visual media and the experiences and stories of friends were also common sources of information. Health/sex education at school was reported least often, although we observed large variations across samples.

The sources of information that shaped students' attitudes toward pregnancy and birth were associated with attitudes toward childbirth technology and interventions among participants (see Table 5). In Table 5 significant associations $(p<0.01)$ between attitudes and sources of information are represented by white cells, and non-significant associations with grey cells $(p>0.01)$. Visual media exposure was generally linked to more favourable attitudes, whereas written media and the experiences and stories of friends had the opposite effect. The stories and experiences of family were not significantly linked to any of the attitudes items, however, reporting school-based sexual health curricula as an influential source was significantly associated with all but one item, indicating that this type of exposure is linked to more favourable attitudes toward childbirth technology and interventions. Having witnessed a birth first hand was linked to attitudes that support judicious use of technology and interventions (see Table 5).

\section{Attitudes toward Childbirth technology and interventions and childbirth fear/confidence in knowledge of pregnancy and birth}

In terms of the standardized cohort, we found variations in the proportion of students with elevated childbirth fear across countries, ranging from $18.5 \%$ in Germany to $39.4 \%$ in England. Proportions were lower in Canada (19.7\%), Chile (22.0\%) and Iceland (21.6\%) and higher in Australia (31.6\%), NZ (31.6\%) and the US (30.3\%).

Students who scored above the $75^{\text {th }}$ percentile on the CFPP scale were significantly more likely to agree with all items, except 'Birth technology should only be reserved for those women who need it'. Students with elevated childbirth fear were significantly more likely to disagree with this item. Students who agreed they felt confident in their level of knowledge about pregnancy and birth were generally less likely to support the use of childbirth technology and interventions (see Table 6). 


\section{Discussion}

To our knowledge, this is the first cross-country study to explore attitudes towards childbirth technology and interventions in the next generation of maternity users. About half of the respondents believed that childbirth technology and interventions make birth easier, protect babies from harm and are a reproductive right. However, somewhat paradoxically, only one in four believed that childbirth requires reliance on medical interventions, and far smaller numbers (one in ten) believed that birth technology is necessary to deliver a child. Respondents had the highest degree of consensus about items measuring the perceived convenience and safety associated with childbirth technology and interventions (as indicated by small standard deviations around the mean for these items).

Positive attitudes towards childbirth technology and interventions in our sample were also linked to childbirth fear and were more common among younger respondents. These same associations were reported for a sample of 836 pregnant women from Israel. Israeli women who reported more favourable views towards the medicalization of childbirth tended to be younger, and were more likely to report childbirth fear. The study from Israel also established a link between favourable attitudes towards childbirth technology and interventions and an increased likelihood of instrumental vaginal delivery or emergency cesarean section (33).

Results revealed divergent attitudes toward childbirth technology and interventions across samples, and highlight the complexities of how birth technology and interventions are constructed and understood among the next generation of maternity care users in different countries.

Attitudes toward birth must be viewed in the context of particular maternity care systems and birthing cultures. For example, Icelandic students were the least likely to agree that it is a woman's right to choose a cesarean birth even if there are no medical indications (34.7\%). In Iceland, healthy women are actively encouraged to have a vaginal birth and choosing a cesarean birth is only possible after a consultation with an obstetrician. Furthermore, the cesarean birth rate in Iceland (15.5\%) is the lowest among OECD countries (28) contributing to a cultural context where a cesarean birth is not considered the norm. In contrast, Chilean students had one of the highest rates of agreement with the same statement (61.4\%). Chile has a very high rate of cesarean section - 50\% in 2015 (40.9\% in public and 69\% in private health) (34) - with expedited access to cesarean by maternal request in the private sector.

We also found a significant association between national cesarean rates and the belief that women should be able to choose a cesarean section without medical indications, further supporting a link between acceptance of maternal request for cesarean and childbirth practices at 
the country-level. These results demonstrate the potential influence of the medicalization of childbirth on the birth attitudes and preferences of the next generation of maternity care users. Because choices are socially constructed (10) and the values and ideas that restrict choices are shaped by political, social, economic and cultural interests (35), Bergeron questions whether caesarean on maternal request "actually furthers gender justice or, on the contrary, if it merely masquerades as increased autonomy while serving interests unrelated to women's health and welfare" (24, p.479). For example, a recent systematic review and meta-analysis found that cesarean section rates are $40 \%$ higher at for-profit hospitals compared to non-for profit hospitals, regardless of women's risk profiles (37). While policies and guidelines about maternal request cesareans for women with no medical indications vary by country, region and hospital, there is growing consensus that maternity care systems must be responsive to women's needs and preferences, and that the informed choices of women should be supported by care providers (38). In our study, 59\% of women and men under 20 years of age supported the view that women should be able to choose a cesarean without medical indications, versus $44 \%$ of students over 30 . The stronger support for women's autonomy in decision-making around mode of birth and childbirth technology and interventions in general among younger students might imply a shift in attitudes towards birth, mirroring the move towards women-led maternity care described above. On the other hand, it could simply be that the older respondents are closer to making actual childbirth decisions, and that this shifts a theoretical attitude of support for birth technology towards an increasing desire to give birth without intervention. This tendency has been shown in longitudinal studies through pregnancy, demonstrating higher rates of preference for a cesarean in early pregnancy interviews than in those conducted towards the end of pregnancy (39).

It is of interest that, across all the included countries, respondents were much more likely to report that childbirth technology and interventions kept babies safe than report that such interventions were needed for the process of childbirth itself. The assumed moral and ethical overlay is that about half of the students believe that women should be prepared to accept interventions that might not be necessary and may even harm them, for the sake of their babies. Social pressure to use the latest and most expensive intervention, implies that mothers who reject childbirth technology and interventions are denying their infants the highest and safest level of care. Such ideologies become social memes that are hard to resist. $(40,41)$

When ranking the items (for the standardized cohort), we found that students from the US showed the overall strongest support for childbirth technology and interventions and students from NZ the weakest support. The maternity care systems in these countries are quite 
different, and might explain the observed differences. For example, a midwife attends every birth in New Zealand, women can access lead maternity care providers who offer continuity of care (most of whom are midwives), and healthy women have the option to give birth at home or in birthing centers. The cesarean rate in NZ is $25.3 \%$, one in four women have an epidural during labour and maternity care providers are salaried (17). In contrast, in the US access to midwives and out-of hospital birth options is limited, the cesarean rate is $31.9 \%$, epidural use during labour is high (71\%), and most obstetricians (who provide the majority of maternity care) are compensated on a fee for service basis (17).

However, it is noteworthy that Chile scored in the middle when we ranked and summed the items that measure attitudes towards childbirth technology and interventions (see Table 3) despite the high rates of elective interventions in the country. In other words, we did not see evidence that attitudes towards childbirth technology and interventions among Chilean students mirrored obstetric practices in that country. Resistance towards childbirth technology and interventions among Chilean students may in part be due to high levels of public debate about 'obstetric violence' and pressure to have unnecessary interventions in many Latin American countries. Indeed, as Locke notes "people everywhere resist, circumvent, reinvent, and pragmatically adapt and adjust to the various biomedical technologies that appear in their communities" (p.28) (42).

Written information about pregnancy and birth, stories of friends and witnessing a birth first-hand were sources of information that were linked to more critical reflections on use of childbirth technology in our study. However, school-based health and sex education and media depictions of pregnancy and birth appear to perpetuate cultural norms that value technology. Analysis of reality birth shows in the US revealed that complex cases are overrepresented, and childbearing women are often shown as passive recipients of life saving interventions (43)(44). Those who opted for natural birth were shown to be in intolerable pain and out of control (44). A recent review of media representations of pregnancy and birth found that normal portrayals of birth are scarce (45). It is reasonable to view media depictions of pregnancy and birth as having a pervasive effect on young adults' constructions of birth, by inflating perceptions that birth is risky, glorifying childbirth technology, and trivializing adverse effects of surgical delivery and other interventions.

Interestingly, attitudes toward childbirth technology and interventions were not linked to learning about pregnancy and birth through the stories and experiences of family members. However, to some extent this may portray an unconscious acceptance of technology and 
interventions, as previous research with university students in the US has shown that a family history of cesarean birth significantly increased the odds that young women preferred a cesarean (24).

The content and impact of school-based health and sex education on attitudes toward birth is poorly understood and warrants further research. Curricula about pregnancy and birth are likely not standardized, evidence-based or tailored to the learning needs of children, youth and young adults. Educational sessions about pregnancy and birth that are delivered by midwives have shown promising results, including increases in knowledge of pregnancy and birth and reductions in childbirth worries among German primary school students (46).

Exposing young people to first hand experiences with birth is a strategy that was linked to more critical reflection about childbirth interventions in the current study. In previous studies, witnessing a birth first hand and learning about pregnancy and birth from friends were both associated with statistically significant lower odds of reporting childbirth fear (47). However, observing a birth or hearing about it from friends might not always translate into a desire for a birth free from technology and interventions, particularly in countries where obstetric interventions are common and normalized, as demonstrated by findings from a qualitative study in Chile. (48)

\section{Limitations}

The convenience sampling and low response rates make it unlikely that our sample is representative of university/ college students across the countries studied. While the correlational analysis does not imply causation, it is more likely that students' attitudes toward childbirth technology and interventions are affected by the degree of medicalization in the country than the other way around. Finally, we used a standardized cohort when comparing attitudes across countries. However, within the 18-25 age bracket, US students were clustered around the lower limit of the range and Chilean student around the higher limit. Given our finding that age was linked to attitudes toward childbirth technology and interventions, it would have been preferable to compare across a smaller age bracket or to provide age-standardized attitude estimates (i.e. attitudes for all 20-year olds in the sample). However, our sample size was too small for such an analysis. Despite these limitations, the results provide important information about how women and men who plan to have children in a range of cultural settings with different maternity care systems think about childbirth technology and interventions. 


\section{Conclusions}

Attitudes about the ease, convenience and safety of childbirth technologies and interventions, as well as constructions of technical interventions as a reproductive right, appear to be mediated by cultural norms. On the other hand, attitudes that reflect unqualified acceptance of interventions, such that birth technology is necessary to deliver a child, are much less prevalent, and not linked to the degree of medicalization in the country or mass-mediated depictions of pregnancy and birth.

As part of global efforts to reduce rates of unnecessary interventions, more critical reflection on childbirth technology and interventions is needed by the next generation of maternity care users. This includes countering negative visuals of childbirth in the media, decreasing fear and increasing confidence in childbirth, especially in countries where high levels of interventions exist, and where they reciprocally shape ongoing culture norms, attitudes, and expectations. 


\begin{tabular}{|c|c|c|}
\hline & $\begin{array}{l}\text { Perceptions about Pregnancy, Labour \& Birth } \\
\text { The following items assess your attitudes and feelings towards pregnancy, labour, and birth. } \\
\text { Please note that you do not need to currently be in a relationship to rate these statements. } \\
\text { Please rate how strongly you agree or disagree with the following statements by clicking one } \\
\text { of the } 6 \text { response options below. }\end{array}$ & \begin{tabular}{|l} 
Item was \\
included \\
in 2006 \\
Canadian \\
survey
\end{tabular} \\
\hline 1 & I am worried that labour pain will be too intense & $\sqrt{ }$ \\
\hline 2 & I feel I (my partner) will not be able to handle the pain of childbirth & $\sqrt{ }$ \\
\hline 3 & I am afraid that I (my partner) might panic and not know what to do during labour \& birth & $\sqrt{ }$ \\
\hline 4 & I am fearful of birth & $\sqrt{ }$ \\
\hline 5 & I am worried that harm might come to the baby & \\
\hline 6 & I am afraid that I (my partner) will be out of control during labour and birth & \\
\hline 7 & I fear complications during labour and birth & \\
\hline \multirow[t]{2}{*}{8} & Birth is unpredictable and risky & \\
\hline & $\begin{array}{l}\text { Perceptions of Birth Technology } \\
\text { The next few questions are assessing your attitudes about the use of technology during labour } \\
\text { and birth. Birth technology includes fetal heart monitors, drugs (e.g. to start and augment } \\
\text { natural labour, epidural anaesthesia to reduce labour pain) and obstetric procedures (such as } \\
\text { Caesarean birth). }\end{array}$ & \\
\hline 9 & Birth technology makes birth easier & $\sqrt{ }$ \\
\hline 10 & Birth technology protects my baby from harm & $\sqrt{ }$ \\
\hline 11 & Birth technology should only be reserved for those women who need it & $\sqrt{ }$ \\
\hline
\end{tabular}




\begin{tabular}{|l|l|l|}
\hline 12 & Birth technology is necessary to deliver a child & $\sqrt{ }$ \\
\hline 13 & Childbirth requires a reliance on medical interventions, even in uncomplicated pregnancies & $\sqrt{ }$ \\
\hline & Perceptions of Caesarean Birth & \\
\hline 14 & I would prefer (my partner) having a Caesarean birth to avoid the pain of childbirth & $\sqrt{ }$ \\
\hline 15 & $\begin{array}{l}\text { I believe it is a woman's right to choose to have a Caesarean birth even if there are no medical } \\
\text { indications }\end{array}$ & $\sqrt{ }$ \\
\hline 16 & The surgical procedure involved in a Caesarean birth does not worry me & $\sqrt{ }$ \\
\hline 17 & Having babies by Caesarean birth is less embarrassing than having them vaginally & $\sqrt{ }$ \\
\hline 18 & I regard vaginal birth as an outdated method of childbirth & $\sqrt{ }$ \\
\hline & After Birth & \\
\hline 19 & A woman's body recovers faster from a Caesarean birth compared with a vaginal birth. & $\sqrt{ }$ \\
\hline 20 & Changes that might occur to a woman's vaginal area after a vaginal birth are a concern for me & $\sqrt{ }$ \\
\hline 21 & I am afraid of what the labour and birth process will do to my (my partner's) body & $\sqrt{ }$ \\
\hline 22 & I am afraid that my (my partner's) body will never be the same again after birth & $\sqrt{ }$ \\
\hline
\end{tabular}


Table 2: Socio-demographic characteristics $(n=4569)$

\begin{tabular}{|l|c|}
\hline Socio-demographic characteristics & $\mathrm{n}(\%)$ \\
\hline Country & \\
Australia & $744(16.3)$ \\
NZ & $411(9.0)$ \\
UK & $348(7.6)$ \\
USA & $491(10.7)$ \\
Canada & $262(5.7)$ \\
Chile & $772(16.9)$ \\
Germany & $981(21.5)$ \\
Iceland & $560(12.3)$ \\
\hline Region of birth & \\
Europe & $1902(41.6)$ \\
Australia/Oceania & $786(17.2)$ \\
Central or South America & $752(16.5)$ \\
North America & $665(14.6)$ \\
Asia & $189(4.1)$ \\
Africa & $55(1.2)$ \\
West Central Asia/Middle East & $36(0.8)$ \\
Other or Missing & $184(4.0)$ \\
\hline Field of Study & \\
Arts/Humanities & \\
Health Sciences & $2034(44.5)$ \\
Science/Engineering & $1351(29.6)$ \\
Other or Missing & $597(13.1)$ \\
\hline & $587(12.8)$ \\
\hline
\end{tabular}




\begin{tabular}{|l|c|}
\hline Highest level of education & \\
High School completed & $1206(26.4)$ \\
Some college or university courses & $1317(28.8)$ \\
College/TAFE diploma & $231(5.1)$ \\
University degree & $1149(25.1)$ \\
Post-graduate degree & $661(14.5)$ \\
Other or Missing & $5(0.1)$ \\
\hline Marital Status & \\
Single & $2459(53.8)$ \\
Married & $277(6.1)$ \\
In a dating relationship & $1809(39.6)$ \\
Separated, divorced, or widowed & $19(0.4)$ \\
Other or Missing & $5(0.1)$ \\
\multicolumn{2}{|}{} \\
\hline
\end{tabular}


Table 3: Attitudes toward childbirth technology and interventions, for the full sample $(n=4569)$ and by country ( $n=2310$; standardized cohort)

\begin{tabular}{|c|c|c|c|c|c|c|c|c|c|c|}
\hline Attitude items & $n$ & $\begin{array}{c}\text { Full sample } \\
\begin{array}{c}(\mathrm{n}=4569) \\
\mathrm{n}(\%)\end{array}\end{array}$ & $\begin{array}{c}\text { Australia } \\
(n=266) \\
n(\%)\end{array}$ & $\begin{array}{c}N Z \\
(n=187) \\
n(\%)\end{array}$ & $\begin{array}{c}\text { UK } \\
(n=220) \\
n(\%)\end{array}$ & $\begin{array}{c}\text { USA } \\
(n=292) \\
n(\%)\end{array}$ & $\begin{array}{c}\text { Canada } \\
(\mathrm{n}=127) \\
\mathrm{n}(\%)\end{array}$ & $\begin{array}{c}\text { Chile } \\
\text { (n=132) } \\
n(\%)\end{array}$ & $\begin{array}{c}\text { Germany } \\
(n=629) \\
n(\%)\end{array}$ & $\begin{array}{c}\text { Iceland } \\
\text { (n=344) } \\
n(\%)\end{array}$ \\
\hline $\begin{array}{l}\text { Birth technology } \\
\text { makes birth easier }\end{array}$ & 4224 & $2355(55.8)$ & $148(55.6)$ & $81(43.3)$ & $107(48.6)$ & $215(73.6)$ & $66(52.0)$ & $60(45.5)$ & $331(52.6)$ & 205 (59.6) \\
\hline $\begin{array}{l}\text { Birth technology } \\
\text { protects my baby } \\
\text { from harm }\end{array}$ & 4223 & $2074(49.1)$ & $110(41.4)$ & 74 (39.6) & $96(43.6)$ & $165(56.7)$ & $63(49.6)$ & $46(34.8)$ & $304(48.3)$ & $199(57.8)$ \\
\hline $\begin{array}{l}\text { Birth technology } \\
\text { should only be } \\
\text { reserved for those } \\
\text { women who need it }\end{array}$ & 4222 & 1029 (24.4) & 55 (20.7) & $45(24.1)$ & $58(26.4)$ & 41 (14.1) & $36(28.3)$ & $53(40.2)$ & 19 (18.9) & $66(19.2)$ \\
\hline $\begin{array}{l}\text { Childbirth requires } \\
\text { reliance on medical } \\
\text { interventions, even } \\
\text { in uncomplicated } \\
\text { pregnancies }\end{array}$ & 4217 & $913(21.7)$ & $38(14.3)$ & $22(11.8)$ & $31(14.1)$ & 47 (16.2) & $16(12.6)$ & $22(16.7)$ & $240(38.2)$ & 45 (13.1) \\
\hline
\end{tabular}




\begin{tabular}{|c|c|c|c|c|c|c|c|c|c|c|}
\hline $\begin{array}{l}\text { Birth technology is } \\
\text { necessary to deliver a } \\
\text { child }\end{array}$ & 4220 & $390(9.2)$ & $23(8.6)$ & $14(7.5)$ & $22(10.0)$ & $36(12.3)$ & $7(5.5)$ & 17 (12.9) & $24(3.8)$ & $26(7.6)$ \\
\hline $\begin{array}{l}\text { I believe it is a } \\
\text { woman's right to } \\
\text { choose a Cesarean } \\
\text { birth even if there } \\
\text { are no medical } \\
\text { indications }\end{array}$ & 4207 & $2136(50.8)$ & $168(63.2)$ & $95(50.8)$ & $84(38.2)$ & $184(63.2)$ & $59(46.5)$ & $81(61.4)$ & $268(42.6)$ & $116(34.7)$ \\
\hline
\end{tabular}


Table 4: Attitudes toward childbirth technology and interventions, rank-ordered and summed

\begin{tabular}{|c|c|c|c|c|c|c|c|c|}
\hline Attitude items & NZ & Canada & UK & Chile & Germany & Iceland & Australia & USA \\
\hline 1.Birth technology makes birth easier & 1 & 4 & 3 & 2 & 5 & 7 & 6 & 8 \\
\hline $\begin{array}{l}\text { 2. Birth technology protects my baby from } \\
\text { harm }\end{array}$ & 2 & 6 & 4 & 1 & 5 & 8 & 3 & 7 \\
\hline $\begin{array}{l}\text { 3. Birth technology should only be reserved for } \\
\text { those women who need it } \\
\text { (reverse scored) }\end{array}$ & 4 & 2 & 3 & 1 & 7 & 6 & 5 & 8 \\
\hline $\begin{array}{l}\text { 4. Childbirth requires reliance on medical } \\
\text { interventions, even in uncomplicated } \\
\text { pregnancies }\end{array}$ & 1 & 2 & 4 & 7 & 8 & 3 & 5 & 6 \\
\hline $\begin{array}{l}\text { 5. Birth technology is necessary to deliver a } \\
\text { child }\end{array}$ & 3 & 2 & 6 & 8 & 1 & 4 & 5 & 7 \\
\hline $\begin{array}{l}\text { 6. I believe it is a woman's right to choose a } \\
\text { Cesarean birth even if there are no medical } \\
\text { indications }\end{array}$ & 5 & 4 & 2 & 6 & 3 & 1 & 7 & 7 \\
\hline Total score & 16 & 20 & 22 & 25 & 29 & 29 & 31 & 43 \\
\hline
\end{tabular}

Note: Countries are assigned ranks, from the lowest to highest proportion of students agreeing with each item in Table 3. Ranks are reversed for item 3. Higher scores indicate stronger support for childbirth technologies and interventions 
Table 5: Relationship between attitudes toward childbirth technology and interventions and sources that shaped students' attitudes (full sample $\mathrm{n}=4569$ )

\begin{tabular}{|c|c|c|c|c|c|c|}
\hline Attitude items & Visual Media & $\begin{array}{l}\text { Written } \\
\text { media }\end{array}$ & Friends & Family & School & $\begin{array}{l}\text { Witnessed } \\
\text { birth first } \\
\text { hand }\end{array}$ \\
\hline $\begin{array}{l}\text { Birth technology makes } \\
\text { birth easier }\end{array}$ & $\uparrow<0.001$ & 0.995 & $\downarrow 0.008$ & 0.485 & $\uparrow<0.001$ & $\downarrow<0.001$ \\
\hline $\begin{array}{l}\text { Birth technology protects } \\
\text { my baby from harm }\end{array}$ & 0.038 & 0.318 & 0.124 & 0.767 & $\uparrow 0.007$ & 0.075 \\
\hline $\begin{array}{l}\text { Birth technology should } \\
\text { only be reserved for those } \\
\text { women who need it }\end{array}$ & 0.028 & $\uparrow 0.001$ & $\uparrow<0.001$ & 0.915 & $\downarrow 0.005$ & $\uparrow<0.001$ \\
\hline $\begin{array}{l}\text { Childbirth requires reliance } \\
\text { on medical interventions, } \\
\text { even in uncomplicated } \\
\text { pregnancies }\end{array}$ & 0.055 & $\downarrow<0.001$ & 0.570 & 0.758 & $\downarrow 0.01$ & 0.663 \\
\hline $\begin{array}{l}\text { Birth technology is } \\
\text { necessary to deliver a child }\end{array}$ & 0.874 & 0.611 & 0.679 & 0.106 & 0.288 & 0.425 \\
\hline
\end{tabular}




\begin{tabular}{|l|l|l|l|l|l|l|}
\hline $\begin{array}{l}\text { I believe it is a woman's } \\
\text { right to choose a Cesarean } \\
\text { birth even if there are no } \\
\text { medical indications }\end{array}$ & $\uparrow 0.01$ & 0.687 & $\downarrow 0.009$ & 0.326 & $\uparrow<0.001$ & $\downarrow<0.001$ \\
\hline
\end{tabular}

$P$ values are listed in each cell; gray cells represent non-significant associations or $p$ values $>0.01$. For $p$ values of 0.01 or less the arrow indicates the direction of the significant difference, e.g. $\uparrow$ means a positive association and $\downarrow$ a negative association. Associations with $p$ values between 0.05 and 0.02 are described as trends. 
Table 6: Relationship between attitudes toward childbirth technology and interventions, childbirth fear and confidence in knowledge of pregnancy and birth (full sample)

\begin{tabular}{|c|c|c|c|c|c|c|c|c|}
\hline Attitude items & $\mathrm{n}$ & $\begin{array}{c}\text { No/low } \\
\text { childbirth } \\
\text { fear } \\
\%\end{array}$ & $\begin{array}{l}\text { Moderate/ } \\
\text { high } \\
\text { childbirth } \\
\text { fear } \\
\\
\%\end{array}$ & $p$ & $\mathrm{n}$ & $\begin{array}{c}\text { No/low } \\
\text { confidence } \\
\\
\%\end{array}$ & $\begin{array}{c}\text { Moderate/ } \\
\text { high } \\
\text { confidence } \\
\\
\%\end{array}$ & $p$ \\
\hline $\begin{array}{l}\text { Birth technology makes birth } \\
\text { easier }\end{array}$ & 4146 & 51.9 & 68.6 & $<0.001$ & 4164 & 57.5 & 51.5 & $<0.001$ \\
\hline $\begin{array}{l}\text { Birth technology protects my } \\
\text { baby from harm }\end{array}$ & 4145 & 46.7 & 57.5 & $<0.001$ & 4163 & 50.3 & 46.4 & 0.022 \\
\hline $\begin{array}{l}\text { Birth technology should only be } \\
\text { reserved for those women who } \\
\text { need it }\end{array}$ & 4153 & 25.4 & 21.4 & 0.01 & 4163 & 21.0 & 33.1 & $<0.001$ \\
\hline $\begin{array}{l}\text { Birth requires reliance on } \\
\text { medical interventions, even in } \\
\text { uncomplicated pregnancies }\end{array}$ & 4149 & 18.8 & 31.3 & $<0.001$ & 4157 & 20.0 & 25.5 & $<0.001$ \\
\hline
\end{tabular}




\begin{tabular}{|l|l|l|l|l|l|l|l|}
\hline $\begin{array}{l}\text { Birth technology is necessary to } \\
\text { deliver a child }\end{array}$ & 4154 & 6.7 & 18.0 & $<0.001$ & 4162 & $9.5 \%$ & $8.7 \%$ \\
\hline $\begin{array}{l}\text { I believe it is a woman's right to } \\
\text { choose a Cesarean birth even if } \\
\text { there are no medical indications }\end{array}$ & 4158 & 47.1 & 62.7 & $<0.001$ & 4168 & 53.7 & 43.8 \\
\hline
\end{tabular}


Figure 1: Sources of information that shaped students' attitudes toward pregnancy \& birth: Standardized cohort, stratified by country ( $\mathrm{n}=2310$ )

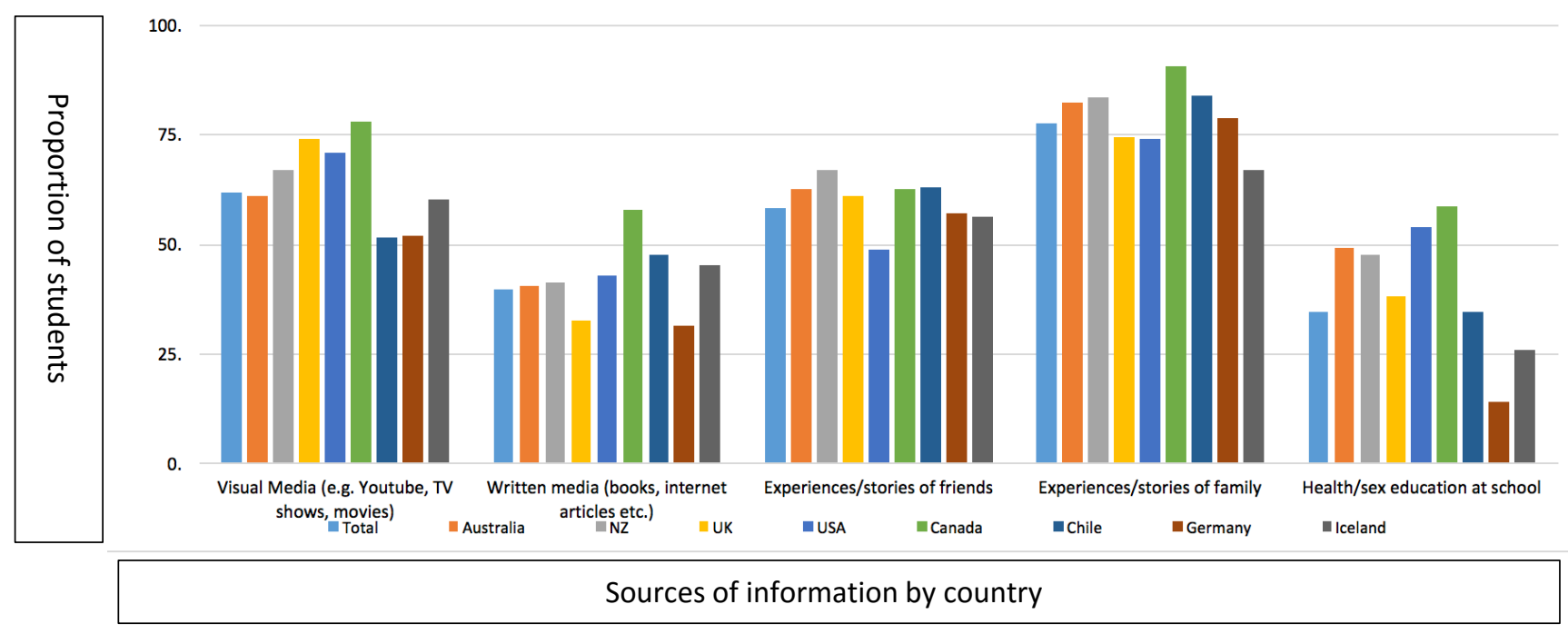




\section{References}

1. Dictionary.com [cited 2017 Sep 8]. Available from: http://www.dictionary.com/browse/technology

2. Jordan B. Birth in Four Cultures: A Crosscultural Investigation of Childbirth in Yucatan, Holland, Sweden, and the United States. Waveland Press; 1993. 235 pages.

3. Cherniak D, Fisher J. Explaining obstetric interventionism: Technical skills, common conceptualisations, or collective countertransference? Womens Stud Int Forum. 2008 Jul;31(4):270-7.

4. Jordan B. The Hut and the Hospital: Information, Power and Symbolism in the Artifacts of Birth. Birth - Issues Perinat Care. 1987;14(1):3640.

5. Fox B, Worts D. Revisiting The Critique Of Medicalized Childbirth: A Contribution to the Sociology of Birth. Gend Soc. 1999 Jun;13(3):32646.

6. Reiger K, Dempsey R. Performing birth in a culture of fear: an embodied crisis of late modernity. Heal Sociol Rev. 2006;15(4):364-73.

7. Jordan B TA. Competing Technologies in Perinatal Care, A Call for Dialogue between Low- and High-Tech Practitioners. Anthropol News. 2009;50(3):5-6.

8. Heaman M, Gupton A, Gregory D. Factors Influencing Pregnant Women's Perceptions of Risk. MCN Am J Matern Nurs. $2004 ; 29(2): 111$.

9. Kornelsen J, Hutton E, Munro S. Influences on decision making among primiparous women choosing elective caesarean section in the absence of medical indications: Findings from a qualitative investigation. J Obs Gynaecol Can. 2010;32(10):962-9.

10. McAra-Couper J, Jones M, Smythe L. Caesarean-section, my body, my choice: The construction of "informed choice" in relation to intervention in childbirth. Fem Psychol. 2012;22(1):81-97.

11. Helén I. Technics over life: risk, ethics and the existential condition in high-tech antenatal care. Econ Soc. 2004;33(January 2015):28-51.

12. Chadwick RJ, Foster D. Negotiating risky bodies : childbirth and constructions of risk. Health Risk Soc. 2013;0(0):1-16.

13. Scamell M, Alaszewski A. Fateful moments and the categorisation of risk: Midwifery practice and the ever-narrowing window of normality during childbirth. Health Risk Soc. 2012;14(2):207-21. 
14. Lankshear G, Ettorre E, Mason D. Decision-making, uncertainty and risk: Exploring the complexity of work processes in NHS delivery suites. Health Risk Soc. 2005;7(4):361-77.

15. Possamai-Inesedy A. Confining risk: Choice and responsibility in childbirth in a risk society. Heal Sociol Rev. 2006;15(4):406-14.

16. Snowden A, Martin C, Jomeen J, Hollins Martin C. Concurrent analysis of choice and control in childbirth. BMC Pregnancy Childbirth. 2011 Jan;11:40.

17. Shaw D, Guise J, Shah N, Others L, Others M, Others A, et al. Drivers of maternity care in high income countries: can health systems support woman-centred care? Lancet [Internet]. 2016;388(10057):2282-95. Available from: http://dx.doi.org/10.1016/S01406736(16)31527-6

18. Davis-floyd RE. The Technocratic Model Of Birth. 1993;

19. Kornelsen J. Essences and imperatives: an investigation of technology in childbirth. Soc Sci Med. 2005 Oct;61(7):1495-504.

20. Walsh DJ. Childbirth embodiment: Problematic aspects of current understandings. Sociology of Health and Illness. 2010.

21. Stoll K, Hall W a. Attitudes and preferences of young women with low and high fear of childbirth. Qual Health Res. 2013 Nov;23(11):1495-505.

22. Stoll KH, Hauck YL, Downe S, Payne D HW and ICA-P to P (ICAPP) ST. Preference for cesarean section in young nulligravid women in eight OECD countries and implications for reproductive health education. Reprod Health. 2017;4(1):116.

23. Stoll K, Hall WA. Attitudes and Preferences of Young Women With Low and High Fear of Childbirth. 2013;

24. Stoll K, Edmonds JK, Hall WA. Fear of Childbirth and Preference for Cesarean Delivery Among Young American Women Before Childbirth: A Survey Study. Birth. 2015;42(3).

25. Stoll K, Hall W, Janssen P, Carty E. Why are young Canadians afraid of birth? A survey study of childbirth fear and birth preferences among Canadian University students. Midwifery. 2014;30(2):220-6.

26. Green JM, Baston HA. Have women become more willing to accept obstetric interventions and does this relate to mode of birth? Data from a prospective study. Birth. 2007;34(1):6-13.

27. Miller S, Abalos E, Chamillard M, Ciapponi A, Colaci D, Comand?? D, et al. Beyond too little, too late and too much, too soon: a pathway 
towards evidence-based, respectful maternity care worldwide. Vol. 388, The Lancet. 2016. p. 2176-92.

28. OECD indicators 2015. Health at a Glance 2015.

29. World Health Organization (WHO). Process of translation and adaptation of instruments [Internet]. WHO. World Health Organization; 2010 [cited $2017 \mathrm{Jul}$ 25]. Available from: http://www.who.int/substance_abuse/research_tools/translation/en/

30. Stoll K, Hauck Y, Downe S, Edmonds J, Gross MM, Malott A, et al. Cross-cultural development and psychometric evaluation of a measure to assess fear of childbirth prior to pregnancy. Sex Reprod Healthc. 2016;8.

31. Streffing J. Ein Fragebogen zur Angst junger Erwachsener vor Schwangerschaft und Geburt. Unpublished MSc Thesis, Hannover Medical School, 2016

32. Swift EM, Gottfredsdottir H, Zoega H, Gross MM, Stoll K. Opting for natural birth: A survey of birth intentions among young Icelandic women. Sex Reprod Healthc. 2017;11:41-6.

33. Benyamini Y, Molcho ML, Dan U, Gozlan M, Preis H. Women's attitudes towards the medicalization of childbirth and their associations with planned and actual modes of birth. Women and Birth. 2017;

34. Instituto Nacional de Derechos Humanos, Chile. "Situación de los derechos humanos en Chile: Informe Anual 2016".

35. Schumpeter J. Capitalism, Socialism and Democracy. 3rd editio. New York: Harper Perennial; 1950.

36. Bergeron V. The ethics of cesarean section on maternal request: A feminist critique of the American College of Obstetricians and Gynecologists' position on patient-choice surgery. In: Bioethics. 2007. p. 478-87.

37. Hoxha I, Syrogiannouli L, Luta X, Tal K, Goodman DC, da Costa BR, et al. Caesarean sections and for-profit status of hospitals: systematic review and meta-analysis. BMJ Open. 2017;7(2):e013670.

38. National Institute for Health and Care Excellence. Caesarean section- Clinical guideline 132. 2012.

39. Kingdon C, Neilson J, Singleton V, Gyte G, Hart A, Gabbay M, et al. Choice and birth method : mixed-method study of caesarean delivery for maternal request. 2009;5-13.

40. De Vries R. Obstetric Ethics and the Invisible Mother. Narrat Inq Bioeth [Internet]. 2017;7(3):215-20. Available from: https://www.lib.uwo.ca/cgi- 
bin/ezpauthn.cgi?url=http://search.proquest.com/docview/1978314791?accountid=15115\%0Ahttp://vr2pk9sx9w.search.serialssolutions .com?ctx_ver=Z39.88-2004\&ctx_enc=info:ofi/enc:UTF-8\&rfr_id=info:sid/ProQ\%3Amedline\&rft_val_fmt=info:of

41. Nilsson C. The delivery room: Is it a safe place? A hermeneutic analysis of women's negative birth experiences. Sex Reprod Healthc. 2014;5(4):199-204.

42. Lock, M \& Nguyen V. An Anthropology of Biomedicine. Wiley-Blackwell; 2010. 518 p.

43. Bak C. Cultural lack of birth experience empowers media representations, not women. Midwifery Today Int Midwife. 2004;72:44-5.

44. Morris T, McInerney K. Media representations of pregnancy and childbirth: An analysis of reality television programs in the United States. Birth. 2010;37(2):134-40.

45. Luce A, Cash M, Hundley V, Cheyne H, Teijlingen E Van, Angell C. "Is it realistic ? " the portrayal of pregnancy and childbirth in the media. BMC Pregnancy and Childbirth; 2016;1-10.

46. Pflanz M. Warum Babys im Fruchtwasser nicht ertrinken können. Evaluation des Modelprojektes " Hebammen in der Schule“ (translation: Why Babies don't drown in the womb: Evaluation of the pilot project "Midwives at School".

47. Stoll K, Hall W. Vicarious Birth Experiences and Childbirth Fear : Does It Matter How Young Canadian Women Learn About Birth ? 2013;22(4):226-34.

48. Sadler M, Rivera M. El temor al parto: Yo no me imagino el parto ideal, yo me imagino el peor de los partos. Rev y Ciencias Sociales. 2015;6:61-72. 
